\title{
A Review of Literature on Optimization of Different Anti Stripping Agents in Construction of Flexible Pavement
}

\author{
Purnima Tripathi ${ }^{1}$ \\ ${ }^{1}$ M. Tech. Scholar, Department of Civil Engineering, \\ BBDU, Lucknow, India
}

\begin{abstract}
This paper presents the effect of anti-stripping additives in bituminous mixes. As per researches series of laboratory tests have been conducted with varying percentage of these Anti-stripping additives, added Individually and in Combinations, to determine their optimum percentages. This paper presents the results of experimental investigations carried out to study the effect of Wetbond-S, Zycotherm and Bitugrip on Bitumen and Aggregate. Boiling water test and Stripping value test were conducted as screening tests. The current research shows the optimization of different antistripping additives to evaluate moisture susceptibilities of bituminous mixes. This paper deals with the review of some previous studies that are done to improve the adhesion between bitumen and aggregate. The stripping value decreases while increasing the percentage of anti-stripping additives to the bitumen.
\end{abstract}

Keywords: Bitumen, Aggregate, Antistripping, Wetbond-S, Zycotherm, Bitugrip, Boiling water test, Stripping value test.

\section{INTRODUCTION}

Road sectors are the engine of growth for economy, employment and empowerment. It is extremely essential that roads are well laid out and strong. In India 95\% of roads are bituminous roads which consists approximately $93-95 \%$ of aggregate and 5-7\% of binder material. In order to cope up with the increasing trend of highly laden vehicles, new innovative materials need to be utilized for highway construction. Moisture damage in asphalt pavement has been considered to be a widespread problem all over India. The moisture damage causes loss of adhesion, and adversely affect to the strength of the asphalt mixture dramatically. It can also cause the premature pavement failures such as rutting and raveling on the pavement surface. During rainy season, the natural bitumen become failure and possess serious problem, to the movement of vehicular traffic.

Stripping is the process that results in separation of asphalt binder and aggregate due to the loss of adhesion at the interface of these materials in the presence of water. In order to control and decrease damaging effects of water, many researchers suggested to apply anti-stripping additives to increase the bond between bitumen and aggregates, leading to improved wetting resistance.

\author{
D. S. Ray ${ }^{2}$ \\ ${ }^{2}$ Professor and Head of Department, Department of Civil \\ Engineering, BBDNITM, Lucknow, India
}

\begin{abstract}
"Wetbond-S" is next generation Nano-technology Silicon based Anti-stripping Additive for Asphalt. This product is a low dose and extremely thermal resistive additive for use in Hot mix and Warm-mix road constructions. This product is specially, suitable for aggregates having very high and tough to control stripping profile. "Wetbond-S" is brownish clear liquid at room temperature with characteristic citrous odour. Acting as an adhesion promoter and water proofing agent. This product is nonmiscible with water and miscible with polar \& hydrocarbon solvents. The thermal stability of this product in hot bitumen (at $160^{\circ} \mathrm{C}$ ) is over 15 days and no additional dose addition/adjustment is required on prolonged storage in hot bitumen in normal course of Hot-mix and Warm-mix pavement constructions.
\end{abstract}

Zycotherm is an odourless nano-technology based product with significant ability to improve the adhesion between bitumen and aggregates in bituminous mixtures. This additive improves the resistance of asphalt mixtures against moisture. It enables complete coating. Zycotherm allows lower mixing temp and lower compaction temp,making Zycotherm an environment friendly warm mix additive.

Bitugrip is product of HINCOAL (Hindustan Colas Private Limited). Hincol Bitugrip is very effective in high rainfall regions, areas with poor aggregate-bitumen affinity and poor drainage systems. It prevents bitumen against the stripping action of water. Hincol Bitugrip is specially designed solution to tackle such problem by enhancing the adhesion of bitumen and ensuring stability of bituminous pavements. Hincol Bitugrip is an amine based antistripping agent that changes interfacial tension between bitumen and aggregates, strengthening the bond for long term durability.

\section{LITERATURE REVIEW}

Cagri Gorkem, Burak Sengoz (2008) ${ }^{\mathbf{1}}$ This study is aimed to determine the effect of additives such as hydrated lime as well as elastomeric (SBS) and plastomeric (EVA) polymer modified bitumen (PMB) on the stripping potential and moisture susceptibility characteristics of hot mix asphalt (HMA) containing different types of aggregate 
(basalt-limestone aggregate mixture and limestone aggregate). The stripping properties and moisture susceptibility characteristics of the samples have been evaluated by means of captured images. As a consequence, it can be concluded that, polymer modified bitumen provides increased adhesion to the aggregate and creates a network structure within the base bitumen.

Yong-Rak Kim, Ingryd Pinto (2011) ${ }^{\mathbf{2}}$ This paper presents performance changes and material characteristics associated with moisture damage due to anti-stripping additives in asphalt mixtures through various laboratory tests. Two additives (hydrated lime and fly ash) are investigated by adding them into two types of mixes where different asphalt binders and aggregates are used. Two mixture constituent tests (the boiling water test and the pull-off tensile strength test) are conducted to characterize the effects of anti-stripping additives on the binderaggregate bonding potential in mixtures. With the limited amount of test data, both hydrated lime and fly ash contribute to reducing moisture damage, which implies potential significant cost savings by the use of fly ash as an alternative additive.

Erol Iskender, Atakan Aksoy (2011) ${ }^{3}$ The aim of this study is to analyze effects of SBS polymer and fatty amine anti-stripping agent additives for asphalt mixtures. The main goal of this research is to investigate rutting and moisture damage problems in asphalt mixtures. Proportional evaluation for stripping was studied and permanent deformation.

Mahmoud Ameri, Sareh Kouchaki (2013) ${ }^{4}$ The objective of this research study was to evaluate moisture susceptibility of hot mix asphalt (HMA) with and without Zycosoil as a nano-organosilane anti-stripping additive and hydrated lime in the form of slurry. It was also observed that the effects of anti-stripping additives on specimens made by siliceous aggregate are more pronounced than those prepared with limestone aggregates. The use of Zycosoil additive will increase adhesion bond between the aggregates and asphalt binders, and in turn influences the moisture resistance of the mixture to moisture damage.

Mahmoud Nazirizad, Amir Kavussi (2015) ${ }^{\mathbf{5}}$ This study is aimed at determining the effects of two different antistripping additives, namely hydrated lime and a liquid antistripping agent (Iterlene In/400-S) on hot mix asphalt (HMA). Moisture susceptibilities of samples were determined by analyzing digital images taken from coated aggregate particles after performing boiling water test. Mixes containing $0.2 \%, 0.3 \%$ and $0.4 \%$ of liquid antistripping agent and mixes containing $1 \%, 1.5 \%$ and $2 \%$ of hydrated lime.

Dae-Wook Park, Woo-Jin Seo (2017) ${ }^{6}$ This paper studied that Evaluation of moisture susceptibility of asphalt mixture using liquid anti-stripping agents. The purposes of this study are to comprehensively evaluate the moisture susceptibility of asphalt mixtures modified with several anti-stripping additives based on laboratory tests. Boiling water test was conducted as a screening test. The addition of anti-stripping agents significantly improves asphalt mixture stripping resistance before and after stripping occurs, and rutting resistance.

Harpreet Singh, Tanuj Chopra (2017) ${ }^{7}$ In this study Zycotherm additive is added to neat bitumen and various comparisons were made using conventional test and rheological test on bitumen. Zycotherm gives better chemical bonding for extended moisture resistance and it ensures about $100 \%$ coating of bitumen at low temperature.

Hasan H. Joni, Mahmood S. Hashim (2017) ${ }^{\mathbf{8}}$ The main objective of this study is determining the effects of two different anti-stripping materials, namely hydrated lime and fly ash on cold bitumen emulsion mixture (CBEMs). It was found that mix samples prepared using hydrated lime additive give greater resistance to water damage, compared with control mixes and those containing fly ash. In addition, using of fly ash gives a high degree of coating and good workability.

Hamed Omrani, Ali Reza Ghanizadeh (2017) ${ }^{\mathbf{9}}$ The primary objective of this study is exploring the moisture susceptibility of unmodified and SBS-modified hot and warm mix asphalt mixtures.

Two different WMA additives including Aspha-min and Sasobit were employed to fabricate WMA specimens. The moisture susceptibility of warm polymer modified asphalt (WPMA) mixes was evaluated. In addition, the effect of different percentages of hydrated lime (from $0 \%$ to $2 \%$ ) and Zycosoil (from $0 \%$ to $0.1 \%$ ) as anti-stripping additives on the moisture susceptibility of the mixtures was explored. The test results showed that increasing moisture content decreases moisture damage resistance. Addition of hydrated lime improves moisture susceptibility. The results also showed that moisture sensitivity was affected significantly by the source of used aggregate.

Kunalkumar Vaghela, Asso. Prof. V.J. Chitaria (2018) ${ }^{\mathbf{1 0}}$ This study investigates the effects of antistripping agent on the microscopic strength of the mineral aggregate contact surface of mixture. The study compared the moisture susceptibility of three variations of bituminous concrete grade 1 mix: (i) Mix without antistripping additive (2) Mix with hydrated lime as an antistripping additive and (3) Mix with Zycosoil as an antistripping additive. The current study resulted in improved bituminous mixtures with the use of antistripping additives, especially in the moisture resistance property of the mixture.

Shazi, Prof. D. S. Ray (2018) ${ }^{\mathbf{1 1}}$ This paper aims at the study of potholes on the bituminous road surface and introducing the antistripping material to the bitumen to increase the durability of the road. In this paper, the antistripping material 'Bitugrip' is used to improve the adhesion properties of bitumen and aggregates. The stripping value decreases while increasing the percentage 
of bitugrip to the bitumen. Overall, the addition of bitugrip has a positive influence on the adhesion properties between the aggregates and the bitumen and can be used to increase the durability of roads, thereby reduce the maintenance cost of the roads.

H. Khani Sanij, P. Afkhamy Meybodi (2018) ${ }^{12}$ The primary goal of these efforts is to improve the durability and load-bearing performance of asphalt mixtures. In this study, glass particles were used, as aggregates in warm mix asphalt (WMA) mixtures. The objective of this study was to investigate the effects the use of Zycotherm ${ }^{\mathrm{TM}}$ as an antistripping agent have on the mechanical properties and moisture susceptibility of glass-asphalt. Four different amounts of Zycotherm ${ }^{\mathrm{TM}}$ were used in WMA mixtures to serve as bitumen modifier and anti-stripping agent. In this study, glass particles were used, as aggregates in warm mix asphalt (WMA) mixtures. Four different amounts of Zycotherm-TM were used in WMA mixtures to serve as bitumen modifier and anti-stripping agent.

\section{CONCLUSIONS}

From the review of literature on different antistripping additives used in bituminous pavement, the following conclusion can be drawn-

- Anti-stripping additives improve the adhesive property.

- These additives enhance the service life of pavement.

- Zycotherm additive decreases penetration value of base bitumen and there was a slight increase in softening point of bitumen with addition of Zycotherm additive.

- Zycotherm additive tends to increase conventional properties of bitumen.

- $\quad$ Based on bitumen test results, Zycotherm ${ }^{\mathrm{TM}}$ addition increases ductility.

- Using Bitugrip increases the durability of the road as proved in the study.

- When bitugrip is mixed with the binder it lowers the surface tension of the bitumen.

- As the bitugrip is of low cost, therefore, it is expected to reduce the life cycle cost of the bituminous pavements.

- Zycosoil improves the moisture resistance and longterm performance of the asphalt mixtures compared with the hydrated lime.

- Anti-stripping additive will make driving safer and easier and to reduce the no. of accidents.

- Further studies can be done on effects of different polymers and anti-stripping agents on moisture sensitivity of WMA mixes produced with various technologies, specifically foaming or water containing ones.

\section{REFERENCES}

[1] Cagri Gorkem, Burak Sengoz (2008), "Predicting stripping and moisture induced damage of asphalt concrete prepared with polymer modified bitumen and hydrated lime". Construction and Building Materials 23 (2009) 2227-2236.

[2] Dae-Wook Park, Woo-Jin Seo(2017), "Evaluation of moisture susceptibility of asphalt mixture using liquid anti-stripping agents". Construction and Building Materials 144 (2017) 399405. Mar, 2017.

[3] Erol Iskender, Atakan Aksoy(2011), "Indirect performance comparison for styrene-butadiene-styrene polymer and fatty amine anti-strip modified asphalt mixtures". Construction and Building Materials 30 (2012) 117-124. Nov,2011.

[4] Hamed Omrani, Ali Reza Ghanizadeh (2017), "Effect of SBS Polymer and Anti-stripping Agents on the Moisture Susceptibility of Hot and Warm Mix Asphalt Mixtures" Civil Engineering Journal Vol. 3, No. 10, October, 2017.

[5] Harpreet Singh, Tanuj Chopra(2017), "Effect Of Zycotherm Performance Of Neat Bitumen And Bituminous Concrete mixes". IJCIET, Volume 8, Issue 8, August 2017

[6] Hasan H. Joni* and Mahmood S. Hashim (2017) "Evaluation of the Effects of Anti-Stripping Materials on the Performance of Cold Bitumen Emulsion Mixtures (CBEMs)". International Journal of Current Engineering and Technology. Sept, 2017.

[7] H. Khani Sanij, P. Afkhamy Meybodi (2018), "Evaluation of performance and moisture sensitivity of glass-containing warm mix asphalt modified with zycotherm ${ }^{\mathrm{TM}}$ as an anti-stripping additive". Construction and Building Materials 197 (2019) 185194. Nov,2018.

[8] Kunal kumar Vaghela, Asso. Prof. V.J. Chitaria (2018), "Evaluation Of Organosilane Based Asphalt Additive For Flexible Pavement”. (IRJET) Volume: 05 Issue: 02 | Feb-2018.

[9] Mahmoud Ameri, Sareh Kouchaki(2013) "Laboratory evaluation of the effect of nano-organosilane anti-stripping additive on the moisture susceptibility of HMA mixtures under freeze-thaw cycles". Construction and Building Materials 48 (2013) 10091016 . July, 2013.

[10] Mahmoud Nazirizad, Amir Kavussi (2015), "Evaluation of the effects of anti-stripping agents on the performance of asphalt mixtures". Construction and Building Materials 84 (2015) 348353.

[11] Shazi, Prof. D. S. Ray (2018), "Study and Evaluation of Disintegration of Pavement Surface”. IJSRD Vol. 6, Issue 03, 2018.

[12] Yong-Rak Kim, Ingryd Pinto(2011), "Experimental evaluation of anti-stripping additives in bituminous mixtures through multiple scale laboratory test results". Construction and Building Materials 29 (2012) 386-393. Oct,2011. 